\title{
Specific Interaction Between Negative Atmospheric lons and Organic Compounds in Atmospheric Pressure Corona Discharge Ionization Mass Spectrometry
}

\author{
Kanako Sekimoto, Mami Sakai, Mitsuo Takayama
}

Graduate School of Nanobioscience, Yokohama City University, 22-2 Seto, Kanazawa-ku, Yokohama, Kanagawa 236-0027, Japan

\begin{abstract}
The interaction between negative atmospheric ions and various types of organic compounds were investigated using atmospheric pressure corona discharge ionization (APCDI) mass spectrometry. Atmospheric negative ions such as $\mathrm{O}_{2}{ }^{-}, \mathrm{HCO}_{3}{ }^{-}, \mathrm{COO}^{-}(\mathrm{COOH}), \mathrm{NO}_{2}{ }^{-}, \mathrm{NO}_{3}{ }^{-}$, and $\mathrm{NO}_{3}{ }^{-}\left(\mathrm{HNO}_{3}\right)$ having different proton affinities served as the reactant ions for analyte ionization in APCDI in negative-ion mode. The individual atmospheric ions specifically ionized aliphatic and aromatic compounds with various functional groups as atmospheric ion adducts and deprotonated analytes. The formation of the atmospheric ion adducts under certain discharge conditions is most likely attributable to the affinity between the analyte and atmospheric ion and the concentration of the atmospheric ion produced under these conditions. The deprotonated analytes, in contrast, were generated from the adducts of the atmospheric ions with higher proton affinity attributable to efficient proton abstraction from the analyte by the atmospheric ion.
\end{abstract}

Key words: Corona discharge, Atmospheric pressure, Negative atmospheric ion, Reactant ion, Proton affinity

\section{Introduction}

$\mathrm{O}$ ne of the most interesting topics in modern mass spectrometry is the development of ambient ionization techniques used to detect chemicals on surfaces in the open air without sample preparation. Desorption electrospray ionization (DESI) and direct analysis in real time (DART), established as the first ambient ionization techniques in 2004 [1] and 2005 [2], respectively, have been largely responsible for the rapid growth of this field, and have led to the proliferation of more than 30 new techniques since their

Electronic supplementary material The online version of this article (doi:10.1007/s13361-012-0363-5) contains supplementary material, which is available to authorized users.

Correspondence to: Mitsuo Takayama; e-mail: takayama@yokohama-cu.ac.jp inception. These developments significantly expand the analyst's toolbox for biological imaging, homeland security detection, and environmental monitoring, as well as in drug discovery, metabolomic, proteomic, forensic, and quality control applications. These ambient ionization techniques often combine separate desorption and ionization processes into a single method. The desorption is carried out using a laser, spray, ultrasound, and hot gases, whereas the ionization goes through either an ESI-like process with charge droplets or an atmospheric pressure chemical ionization (APCI)-like process with reactions involving highly reactive ions or excited neutrals.

The APCI-like ambient ionization sources have frequently employed corona discharge devices, as seen in DART [2], the atmospheric-pressure solids analysis probe (ASAP) [3], and charge assisted laser desorption/ionization (CALDI) [4]. Utilization of corona discharges is advantageous because of the quantitative control of the number of reactant ions for 
ionization (e.g., the atmospheric ions originating from common air constituents). However, current ambient ionization techniques using corona discharges, especially in negative-ion mode, have some problems: (1) Analyte ionization can be inhibited by atmospheric negative ions $\mathrm{R}^{-}$produced due to high $\mathrm{R}$ electron affinities (e.g., the nitrogen oxide anion $\mathrm{NO}_{x}^{-}$ [5]). (2) Atmospheric negative ion species are rather diverse compared with positive ion compounds because of trace gases in the air, and because neutral and radical discharge byproducts, such as $\mathrm{CO}_{2}$ and $\mathrm{NO}_{x}$, are significantly involved in the formation of atmospheric negative ions [6, 7]. Furthermore, the abundances of various atmospheric negative ions occurring in the discharge area vary considerably with the discharge conditions used, and the relationship between the atmospheric negative ion formation and discharge conditions is not yet fully understood $[6,7]$. These problems bring about quite complex mass spectra consisting of not only deprotonated analyte peaks $[\mathrm{M}-\mathrm{H}]^{-}$but also molecular attached and/or fragment ion peaks originating from the interaction between the atmospheric ions and analytes whose intensities differ from experiment to experiment. In order to accurately interpret the negative-ion mass spectra obtained, it is necessary to systematically understand the influence of the individual atmospheric negative ions on analyte ionization. The difficulty in regular formation of specific atmospheric negative ions in corona discharge, however, has resulted in a lack of fundamental studies concerning analyte ionization.

We have recently established an atmospheric pressure DC corona discharge system that leads to the regular formation of various atmospheric negative ions such as $\mathrm{O}_{2}^{-}, \mathrm{CO}_{x}^{-}$, and $\mathrm{NO}_{x}^{-}$by varying the discharge conditions in ambient air without any preparation $[8,9]$. Here, we investigate the interaction between the atmospheric negative ions dominantly formed (i.e., $\mathrm{O}_{2}^{-}, \mathrm{HCO}_{3}^{-}, \mathrm{COO}^{-}(\mathrm{COOH}), \mathrm{NO}_{2}^{-}$, $\mathrm{NO}_{3}^{-}$, and $\mathrm{NO}_{3}{ }^{-}\left(\mathrm{HNO}_{3}\right)$ ), and organic compounds with various properties by using the atmospheric pressure corona discharge ionization (APCDI) mass spectrometry. The results obtained contribute toward an understanding of the influence of atmospheric negative ions on analyte ionization in APCI-like ambient ionization techniques.

\section{Experimental}

\section{Atmospheric Pressure Corona Discharge Ionization (APCDI) Mass Spectrometer}

A schematic illustration of the apparatus used is shown in Figure 1. Discharge experiments were performed under atmospheric pressure in laboratory air, which mainly consists of common air constituents $\mathrm{N}_{2}, \mathrm{O}_{2}, \mathrm{H}_{2} \mathrm{O}$, and $\mathrm{CO}_{2}$. The laboratory temperature of $298 \mathrm{~K}$ and relative humidity of $40 \%-70 \%$ were controlled by a standard commercial airconditioner. The corona needle used as a point electrode was a headless insect pin (Shiga, Tokyo, Japan), made of stainless steel with a diameter of $200 \mu \mathrm{m}$ and $20 \mathrm{~mm}$ in length. The needle tip had a radius of curvature of ca. $1 \mu \mathrm{m}$ and the shape of the tip surface was adequately approximated by hyperboloids of revolution. The opposite electrode was the stainless steel orifice plate of the mass spectrometer. The discharge gap between the electrodes, and the needle angle $\alpha$ with respect to the orifice axis, were adjusted to $3 \mathrm{~mm}$ and between $0-\pi / 2 \mathrm{rad}$, respectively, using a manipulator. An angle of 0 is defined as the needle being located on the orifice axis. DC voltages over the range of 1.9 to $-3.9 \mathrm{kV}$ were applied to the needle relative to the orifice plate in order to establish a stationary electric field between the electrodes. The corona voltages used led to a stable glow corona on the needle tip and brought about an electric current over the range of 3-55 $\mu \mathrm{A}$, which was measured with a micro-ammeter. A micro-ceramic heater was placed between the needle and the orifice plate in order to vaporize condensed-phase analytes. Analytes diffused into the discharge area and were negatively ionized with reactant ions $\mathrm{R}^{-}$. The resulting analyte ions were introduced into the orifice hole with $320 \mu \mathrm{m}$ in diameter and $114 \mathrm{~mm}$ in length. The orifice was heated at $363 \mathrm{~K}$ to prevent the generation of analyte ion- and reactant ion-related large water clusters. The orifice temperature was measured with a thermocouple. The ions were focused onto the skimmer opening by the tube lens and were transported into the ion guide. The voltage applied to the skimmer and tube lens were 0 and $67.8 \mathrm{~V}$, respectively. The applied $\mathrm{rf}$ voltage on the ion guide was $3 \mathrm{~V}$. The transported ions were accelerated to 20 and $5 \mathrm{~V}$ at the focusing lens electrode and then analyzed with a TSQ7000 triple-quadrupole mass spectrometer (Thermo Fisher Scientific, San Jose, CA). The assignment of negative ion species observed was performed by using collisioninduced dissociation (CID). Collision gas and energy (lab.) used were argon at $2.2 \times 10^{-3}$ Torr and $5-25 \mathrm{eV}$, respectively.

\section{Analytes}

Methanol, acetic acid, 2-phenylethanol, phenol, and phenylethylamine were purchased from Wako Pure Chemical Industries (Osaka, Japan). Benzoic acid and aniline were purchased from Tokyo Chemical Industry (Tokyo, Japan). 4Aminobutanoic acid, L-serine, L-lysine, and L-phenylalanine were purchased from Sigma-Aldrich (Tokyo, Japan).

\section{Results and Discussion}

\section{Atmospheric Negative Ions Formed in APCDI}

The use of various discharge conditions with respect to corona voltage $V$ and needle angle $\alpha$ in ambient air brought about the formation of various atmospheric negative ions. The corona voltage and the needle angle determine the electric field strength on the needle tip surface where the field line reaching the orifice arises, the principle factor governing the sequential progress of successive ion-molecule reactions in the formation of various atmospheric negative ions $[8,9]$. The field strength increases with 


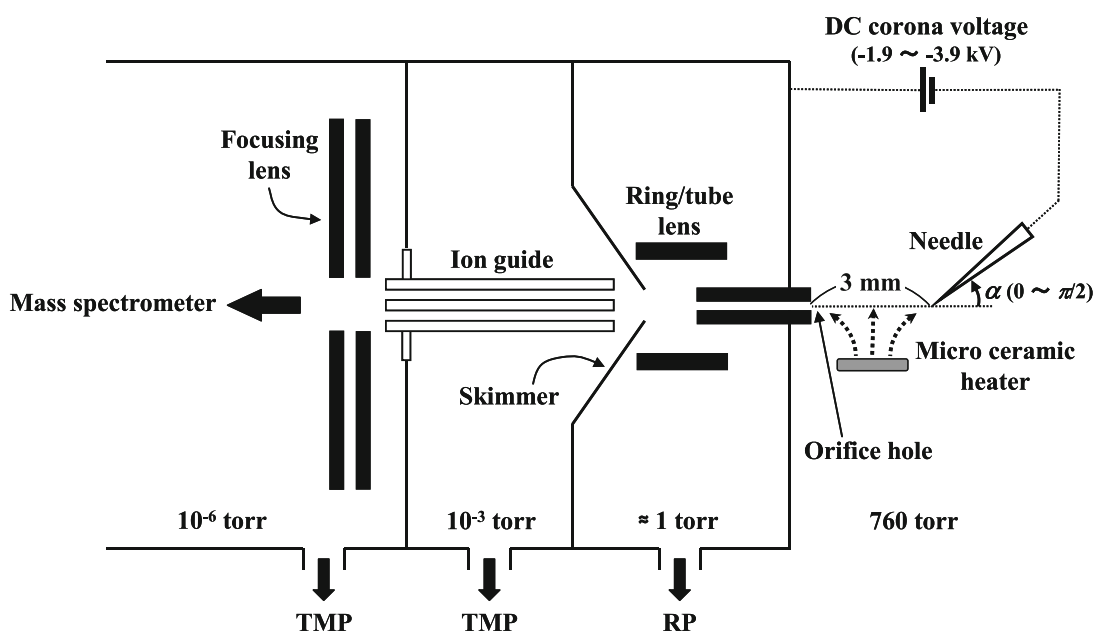

Figure 1. Schematic illustration of an APCDI mass spectrometer

increasing corona voltage from -1.9 to $-3.9 \mathrm{kV}$ and with decreasing needle angle from $\pi / 2$ to 0 , which leads to an increase in needle tip curvature on the tip surface with respect to the orifice. Figure 2 shows typical atmospheric negative ion mass spectra obtained using the following discharge conditions: (a) $(V \mathrm{kV}, \alpha \mathrm{rad})=(-1.9, \pi / 2)$; (b) $(-3.1, \pi / 4)$; (c) $(-2.3,0)$; and (d) $(-3.9,0)$, which brought about the electric currents of $3,23,10$, and $55 \mu \mathrm{A}$, respectively. The dominant atmospheric ions formed at the lowest electric field strength resulting from $(V, \alpha)=(-1.9, \pi / 2)$ were the superoxide anion $\mathrm{O}_{2}^{-}(\mathrm{m} / \mathrm{z} 32)$ and its hydrated clusters $\mathrm{O}_{2}^{-}\left(\mathrm{H}_{2} \mathrm{O}\right)_{n}(m / z 32+18 n)$ as shown in Figure 2a. At medium electric field strength $(V, \alpha)=(-3.1, \pi / 4)$, the negative ions originated from nitrogen dioxide $\mathrm{NO}_{2}$, oxalic acid $(\mathrm{COOH})_{2}$ and carbonic acid $\mathrm{H}_{2} \mathrm{CO}_{3}$, (i.e., primarily $\mathrm{NO}_{2}{ }^{-}$ $\left(\mathrm{H}_{2} \mathrm{O}\right)_{n}(m / z 46+18 n), \mathrm{HCO}_{3}{ }^{-}\left(\mathrm{H}_{2} \mathrm{O}\right) / \mathrm{NO}_{2}{ }^{-}\left(\mathrm{HO}_{2}\right)(m / z 79)$, $\mathrm{NO}_{2}^{-}\left(\mathrm{H}_{2} \mathrm{CO}_{3}\right)(\mathrm{m} / \mathrm{z} 108)$, and $\mathrm{COO}^{-}(\mathrm{COOH})\left(\mathrm{H}_{2} \mathrm{CO}_{3}\right)\left(\mathrm{H}_{2} \mathrm{O}\right)_{n}$ $(\mathrm{m} / \mathrm{z} 151+18 n)$, were generated (Figure $2 \mathrm{~b})$. The high electric field strength due to $(V, \alpha)=(-2.3,0)$ and $(-3.9,0)$ led to the formation of an abundance of $\mathrm{NO}_{3}{ }^{-}$related ions such as $\mathrm{NO}_{3}{ }^{-}$ $\left(\mathrm{H}_{2} \mathrm{CO}_{3}\right)\left(\mathrm{HNO}_{3}\right)_{m}(m=0,1 ; m / z 124,187)$ and $\mathrm{NO}_{3}{ }^{-}\left(\mathrm{HNO}_{3}\right)_{m}$ $(m=1,2 ; m / z 125,188)$ (Figure $2 \mathrm{c}$ and d). The formation mechanism of typical atmospheric negative ions observed here (i.e., $\mathrm{O}_{2}^{-}, \mathrm{HCO}_{3}^{-}, \mathrm{COO}^{-}(\mathrm{COOH}), \mathrm{NO}_{2}^{-}, \mathrm{NO}_{3}^{-}$, and $\mathrm{NO}_{3}^{-}$ $\left.\left(\mathrm{HNO}_{3}\right)_{n}\right)$, and its dependence on electric field strength on the needle tip surface is described below.

The formation of various atmospheric negative ions in atmospheric pressure corona discharges originates from electrons $\gamma$ - and field-emitted from the tip surface of the needle electrode. The collision of those electrons with $\mathrm{N}_{2}$ and $\mathrm{O}_{2}$ leads to the generation of primary ions $\mathrm{N}_{2}{ }^{+}, \mathrm{O}_{2}{ }^{+}$, $\mathrm{O}^{-}, \mathrm{O}_{2}^{-}$, and radicals such as $\mathrm{N}$ and $\mathrm{O}$ in the glow region near the needle tip surface with particularly high electric field strength. In the case of negative corona discharge, primary negative ions move along the field lines towards the orifice as an opposite electrode. Simultaneously, those ions alter more stable ion species or lose charge through a number of collisions with common air constituents and discharge by-products (e.g., neutral species $\mathrm{NO}_{x}$ originating from the radicals $\mathrm{N}$ and $\mathrm{O}$ ) because of the short mean free path of molecule $\lambda_{\mathrm{M}}$ in the discharge area under atmospheric pressure $(66.3 \mathrm{~nm})$. Terminal negative ions generated via successive ion-molecule reactions can reach the orifice and be detected by mass spectrometers. A series of ion-molecule reactions from primary to terminal ions have been called as "ion evolutions."

Figure $3 \mathrm{a}$ shows the proposed ion evolution for the formation of the atmospheric negative ions $\mathrm{O}_{2}^{-}, \mathrm{HCO}_{3}^{-}$, $\mathrm{COO}^{-}(\mathrm{COOH}), \mathrm{NO}_{2}^{-}, \mathrm{NO}_{3}^{-}$, and $\mathrm{NO}_{3}^{-}\left(\mathrm{HNO}_{3}\right)_{n}$, on the basis of previous studies of kinetics and negative corona discharge under ambient air conditions [6-18]. The formation mechanism of neutral species $\mathrm{NO}_{x}$ and $\mathrm{CO}$ as discharge by-products, which are significantly involved in negative ion evolution (shown in Figure 3a), is illustrated in Figure 3b. Elementary processes and corresponding rate constants for ion evolution and $\mathrm{NO}_{x}$ and $\mathrm{CO}$ formation are summarized in Table 1. The sequential progress of negative ion evolution occurring along a certain field line is closely related to the kinetic energy $(K E)$ of electrons emitted from the needle tip surface where the field line arises and the resulting concentration of primary ions $\mathrm{O}^{-}$and $\mathrm{O}_{2}^{-}$and the neutral species $\mathrm{NO}_{x}$ and $\mathrm{CO}$ on the field line. The formation of $\mathrm{O}^{-}$, $\mathrm{O}_{2}^{-}, \mathrm{NO}_{x}$, and $\mathrm{CO}$ requires a sufficient quantity of electrons with kinetic energy of $4.5,0,9.8$, and 8.3 , respectively, as shown in reactions $\mathrm{a}, \mathrm{h}, \mathrm{n}$, and $\mathrm{r}$ in Figure 3 and Table $1[6$, $14,15,18]$. When there are only electrons with low energy nearly zero $(K E \approx 0 \mathrm{eV})$ on a certain needle tip position, the $\mathrm{O}_{2}^{-}$ion can be dominantly formed on the field line, which arises from the tip surface via electron attachment with $\mathrm{O}_{2}$ (reaction $\mathrm{h}$ in Figure 3a [14, 15]). At increasing electron kinetic energy up to $4.5 \mathrm{eV}(K E \approx 4.5 \mathrm{eV})$, the formation of $\mathrm{O}^{-}$due to dissociation ionization of $\mathrm{O}_{2}$ (reaction $\mathrm{a}$ in Figure 3a [6]) becomes dominant, and thus the reaction of $\mathrm{O}^{-}$with $\mathrm{H}_{2} \mathrm{O}$ to form $\mathrm{HO}^{-}$and the subsequent association reaction of $\mathrm{HO}^{-}$with $\mathrm{CO}_{2}$ to form $\mathrm{HCO}_{3}^{-}$mainly occur (reactions $\mathrm{b}$ and $\mathrm{c}$ in Figure $3 \mathrm{a}[10]$ ). In the case of the 

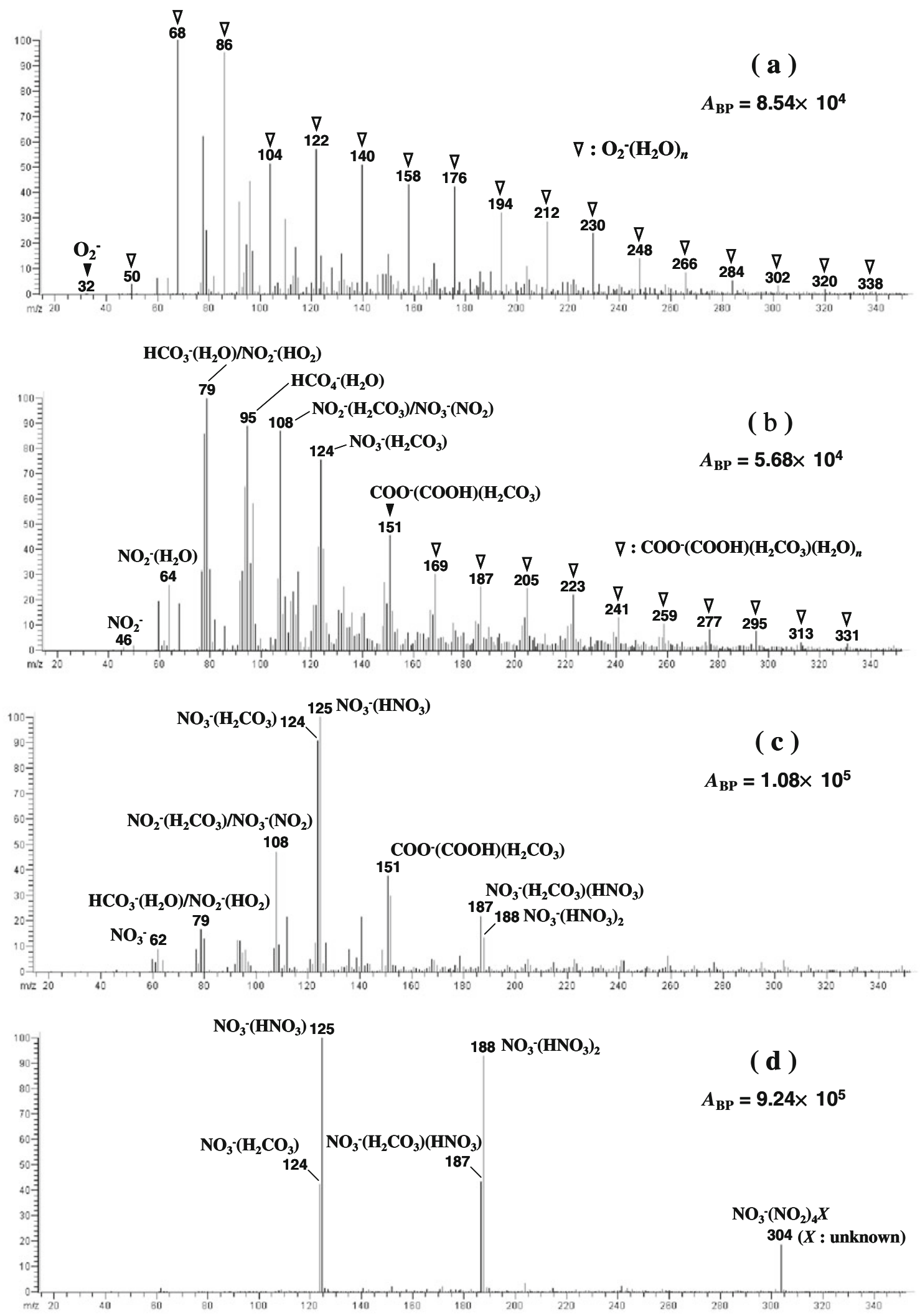

Figure 2. Atmospheric negative ion mass spectra obtained by using the following discharge conditions: (a) $(V \mathrm{kV}, \alpha \mathrm{rad})=(-1.9$, $\pi / 2)$; (b) $(-3.1, \pi / 4)$; (c) $(-2.3,0)$; and (d) $(-3.9,0)$. $A_{\mathrm{BP}}$ represents the absolute abundance [arbitrary unit] of the base peak in each mass spectrum 




( b )

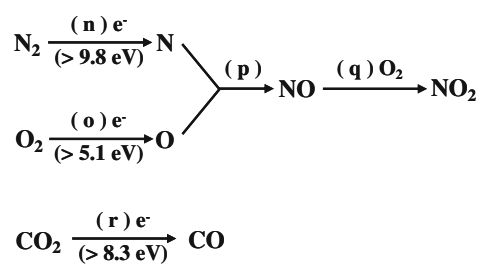

Figure 3. Sequential progress of the ion-molecule reactions for the formation of (a) atmospheric negative ions $\mathrm{O}_{2}{ }^{-}$, $\mathrm{HCO}_{3}{ }^{-}, \mathrm{COO}^{-}(\mathrm{COOH}), \mathrm{NO}_{2}{ }^{-}, \mathrm{NO}_{3}{ }^{-}$, and $\mathrm{NO}_{3}{ }^{-}\left(\mathrm{HNO}_{3}\right)_{n}$, and (b) neutral species $\mathrm{NO}_{x}$ and $\mathrm{CO}$ in negative corona discharge under ambient air conditions

abundant electrons with kinetic energy about $10 \mathrm{eV}(K E \approx$ $10 \mathrm{eV}$ ), the ion evolution involving $\mathrm{NO}_{x}$ and $\mathrm{CO}$ to form $\mathrm{NO}_{x}^{-}$and $\mathrm{COO}^{-}(\mathrm{COOH})$ (reactions $\mathrm{d}-\mathrm{m}$ in Figure 3a [1017]) can start to occur, which originates from charge transfer reaction of $\mathrm{HO}^{-}$with $\mathrm{NO}_{2}$ (reaction $\mathrm{d}$ in Figure 3a [10]). In contrast, the abundant $\mathrm{NO}_{x}$ produced by a number of electrons with particularly high kinetic energy $(K E>10 \mathrm{eV})$ promotes the formation of $\mathrm{HNO}_{3}, \mathrm{NO}_{3}{ }^{-}$, and $\mathrm{NO}_{3}{ }^{-}\left(\mathrm{HNO}_{3}\right)_{n}$ (reactions e-g, j, and k in Figure 3a [10-13, 16]).

It should be noted here that the kinetic energy of electrons involving the negative ion evolution described above is determined by the product of the electric field strength $E$ at the electron emitted position on the needle tip surface and the mean free path of electron $\lambda_{\mathrm{e}}(375 \mathrm{~nm}$ at 760 Torr) (i.e., $K E=E \times \lambda_{\mathrm{e}}$ ). Furthermore, the field strength $E$ is dependent upon the local curvature of each tip position, as well as corona voltage. We previously examined the dependence of the local curvature and corona voltage on the field strength distributions established on the needle tip surface used here. As described in our previous reports $[8,9]$, the tip apex with the highest curvature brings about particularly high field strength above $10^{8} \mathrm{Vm}^{-1}$ at any corona voltages $(-1.9$ to $3.5 \mathrm{kV}$ ), which leads to the generation of electrons with high kinetic energy over the range of 40 to $120 \mathrm{eV}$. Therefore, the discharge conditions of $(V, \alpha)=(-2.3,0)$ and $(-3.9,0)$ in which the field line arising from the tip apex reaches the orifice can bring about the abundant $\mathrm{NO}_{3}{ }^{-}$and $\mathrm{NO}_{3}{ }^{-}\left(\mathrm{HNO}_{3}\right)$ ions due to high field strength and resulting electron kinetic energy described above. In the case of the tip peripheral region with lower curvature, in contrast, the use of various combinations of corona voltage and the local curvature makes it possible to accurately regulate the field strength, which leads to the electron kinetic energy over the range of 0 to $10 \mathrm{eV}$. Thereby, it is most likely that the discharge conditions of $(V, \alpha)=(-1.9, \pi / 2)$ or $(-3.1, \pi / 4)$ bring about the electron kinetic energy nearly zero or over the range of 4.5 to $10 \mathrm{eV}$, and resulting in the dominant detection of $\mathrm{O}_{2}{ }^{-}$ or $\mathrm{HCO}_{3}^{-}, \mathrm{NO}_{2}^{-}$, and $\mathrm{COO}^{-}(\mathrm{COOH})$.

\section{Analyte Ionization Involving Atmospheric Negative Ions}

The various atmospheric negative ions described in the preceding section can serve as reactant ions $\mathrm{R}^{-}$for analyte ionization in APCDI in negative-ion mode. Figure 4 shows

Table 1. Elementary Processes for the Formation of Atmospheric Negative Ions $\mathrm{O}_{2}^{-}, \mathrm{HCO}_{3}^{-}, \mathrm{COO}^{-}(\mathrm{COOH}), \mathrm{NO}_{2}^{-}, \mathrm{NO}_{3}^{-}$, and $\mathrm{NO}_{3}^{-}\left(\mathrm{HNO}_{3}\right)_{n}$, and $\mathrm{Neutral}^{-}$ Species $\mathrm{NO}_{x}$ and $\mathrm{CO}$ in Atmospheric Pressure Corona Discharge and the Rate Constant for Each Process

\begin{tabular}{|c|c|c|c|c|}
\hline & Reaction & Reaction Rate Constant & & References \\
\hline (a) & $\mathrm{O}_{2}^{-}+\mathrm{e}^{-}(>4.5 \mathrm{eV}) \rightarrow \mathrm{O}^{-}+\mathrm{O}$ & - & \multirow{7}{*}{$\left(M=\mathrm{O}_{2}\right)$} & [6] \\
\hline (b) & $\mathrm{O}^{-}+\mathrm{H}_{2} \mathrm{O} \rightarrow \mathrm{HO}^{-}+\mathrm{HO}$ & $<6 \times 10^{-13} \mathrm{~cm}^{3} \mathrm{~s}^{-1}$ & & {$[10]$} \\
\hline (c) & $\mathrm{HO}^{-}+\mathrm{CO}_{2}+M \rightarrow \mathrm{HCO}_{3}^{-}+M$ & $7.6 \times 10^{-28} \mathrm{~cm}^{6} \mathrm{~s}^{-1}$ & & [10] \\
\hline (d) & $\mathrm{HO}^{-}+\mathrm{NO}_{2} \rightarrow \mathrm{NO}_{2}^{-}+\mathrm{HO}$ & $1.5 \times 10^{-9} \mathrm{~cm}^{3} \mathrm{~s}^{-1}$ & & {$[10]$} \\
\hline (e) & $\mathrm{HO}+\mathrm{NO}_{2}+M \rightarrow \mathrm{HNO}_{3}+M$ & $6.7 \times 10^{-11} \mathrm{~cm}^{3} \mathrm{~s}^{-1}$ & & [11] \\
\hline (f) & $\mathrm{NO}_{2}^{-}+\mathrm{NO}_{2} \rightarrow \mathrm{NO}_{3}^{-}+\mathrm{NO}$ & $4.0 \times 10^{-12} \mathrm{~cm}^{3} \mathrm{~s}^{-1}$ & & [12] \\
\hline (g) & $\mathrm{NO}_{2}^{-}+\mathrm{HNO}_{3} \rightarrow \mathrm{NO}_{3}^{-}+\mathrm{HNO}_{2}$ & $1.6 \times 10^{-9} \mathrm{~cm}^{3} \mathrm{~s}^{-1}$ & & [13] \\
\hline \multirow[t]{2}{*}{ (h) } & $\mathrm{O}_{2}+\mathrm{e}^{-}(\approx 0 \mathrm{eV})+M \rightarrow \mathrm{O}_{2}^{-}+M$ & $1.9 \times 10^{-30} \mathrm{~cm}^{6} \mathrm{~s}^{-1}$ & \multirow{3}{*}{$\begin{array}{l}\left(M=\mathrm{O}_{2}\right) \\
\left(M=\mathrm{N}_{2}\right)\end{array}$} & {$[14]$} \\
\hline & & $1.0 \times 10^{-31} \mathrm{~cm}^{6} \mathrm{~s}^{-1}$ & & [15] \\
\hline (i) & $\mathrm{O}_{2}^{-}+\mathrm{NO}_{2} \rightarrow \mathrm{NO}_{2}^{-}+\mathrm{O}_{2}$ & $1.2 \times 10^{-9} \mathrm{~cm}^{3} \mathrm{~s}^{-1}$ & & [10] \\
\hline$(j-1)$ & $\mathrm{O}_{2}^{-}+\mathrm{H}_{2} \mathrm{O}+M \rightarrow \mathrm{O}_{2}^{-}\left(\mathrm{H}_{2} \mathrm{O}\right)+M$ & $2.2 \times 10^{-28} \mathrm{~cm}^{6} \mathrm{~s}^{-1}$ & \multirow{2}{*}{$\left(M=\mathrm{O}_{2}\right)$} & [10] \\
\hline$(\mathrm{j}-2)$ & $\mathrm{O}_{2}^{-}\left(\mathrm{H}_{2} \mathrm{O}\right)+\mathrm{NO} \rightarrow \mathrm{NO}_{3}^{-}+\mathrm{H}_{2} \mathrm{O}$ & $3.1 \times 10^{-9} \mathrm{~cm}^{3} \mathrm{~s}^{-1}$ & & [16] \\
\hline (k) & $\mathrm{NO}_{3}^{-}+\left(\mathrm{HNO}_{3}\right)_{n}+M \rightarrow \mathrm{NO}_{3}^{-}\left(\mathrm{HNO}_{3}\right)_{n}+M$ & $>1 \times 10^{-26} \mathrm{~cm}^{6} \mathrm{~s}^{-1}(n=1)$ & \multirow[t]{9}{*}{$\left(M=\mathrm{N}_{2}\right)$} & [13] \\
\hline$(1-1)$ & $\mathrm{HO}+\mathrm{CO}+M \rightarrow \mathrm{COOH}+M$ & - & & [17] \\
\hline$(1-2)$ & $2 \mathrm{COOH} \rightarrow(\mathrm{COOH})_{2}$ & - & & [17] \\
\hline (m) & $(\mathrm{COOH})_{2}+A^{-} \rightarrow \mathrm{COO}^{-}(\mathrm{COOH})+\mathrm{H} A$ & - & & - \\
\hline (n) & $\mathrm{N}_{2}+\mathrm{e}^{-}(>9.8 \mathrm{eV}) \rightarrow 2 \mathrm{~N}+\mathrm{e}^{-}(\approx 0 \mathrm{eV})$ & - & & [18] \\
\hline (o) & $\mathrm{O}_{2}+\mathrm{e}^{-}(>5.1 \mathrm{eV}) \rightarrow 2 \mathrm{O}+\mathrm{e}^{-}(\approx 0 \mathrm{eV})$ & - & & [18] \\
\hline (p) & $\mathrm{N}+\mathrm{O}+M \rightarrow \mathrm{NO}+M$ & - & & [6] \\
\hline (q) & $2 \mathrm{NO}+\mathrm{O}_{2} \rightarrow 2 \mathrm{NO}_{2}$ & $2.0 \times 10^{-38} \mathrm{~cm}^{6} \mathrm{~s}^{-1}$ & & {$[11]$} \\
\hline (r) & $\mathrm{CO}_{2}+\mathrm{e}^{--}(>8.3 \mathrm{eV}) \rightarrow \mathrm{CO}+\mathrm{O}+\mathrm{e}^{-}(\approx 0 \mathrm{eV})$ & - & & {$[18]$} \\
\hline
\end{tabular}

$M$ : three body; $A^{-}$: Negative ion which has a high proton affinity than $\mathrm{COO}^{-}(\mathrm{COOH})$ 

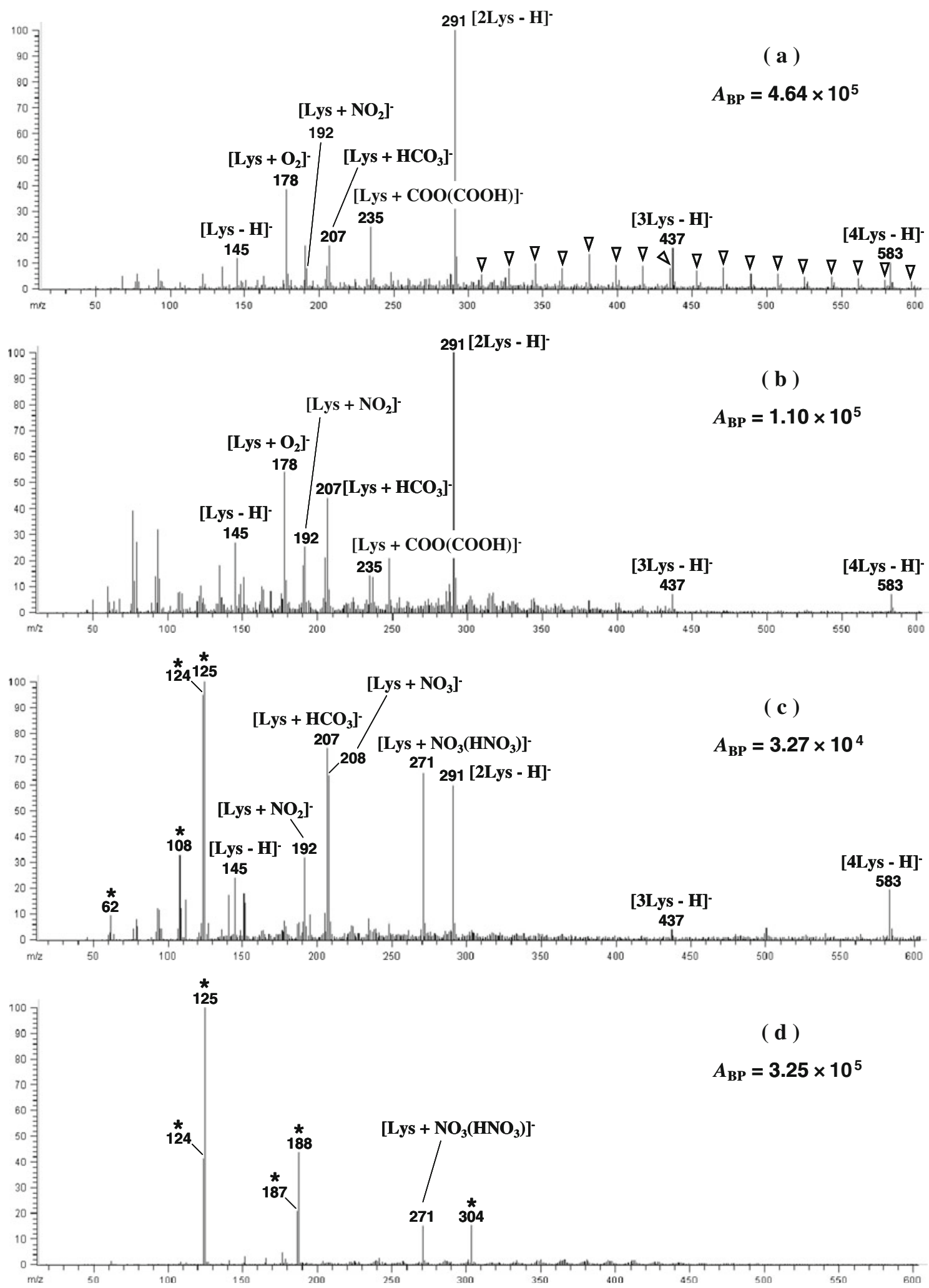

Figure 4. Negative ion mass spectra of L-lysine obtained using the following discharge conditions: (a) $(V \mathrm{kV}, \alpha \mathrm{rad})=(-1.9, \pi / 2)$; (b) $(-3.1, \pi / 4)$; (c) $(-2.3,0)$; and (d) $(-3.9,0)$. The asterisk (*) and $A_{\mathrm{BP}}$ represent the ion peaks of the atmospheric ions shown in Figure 2 and the absolute abundance [arbitrary unit] of the base peak in each mass spectrum, respectively

the negative ion mass spectra of L-lysine ( $\mathrm{Mr} 146)$ obtained using the following discharge conditions: (a) $(V \mathrm{kV}, \alpha \mathrm{rad})=$
$(-1.9, \pi / 2)$; (b) $(-3.1, \pi / 4)$; (c) $(-2.3,0)$; and (d) $(-3.9,0)$. The resulting electric currents were same as when measuring 
without analytes. The major ion peaks related to lysine in the mass spectra were assigned as deprotonated lysine clusters $[n \text { Lys }-\mathrm{H}]^{-}(n=1-4 ; m / z 145,291,437,583)$ and adducts with atmospheric ions such as $\mathrm{O}_{2}^{-}, \mathrm{HCO}_{3}{ }^{-}, \mathrm{COO}^{-}(\mathrm{COOH})$, $\mathrm{NO}_{2}^{-}, \mathrm{NO}_{3}^{-}$, and $\mathrm{NO}_{3}^{-}\left(\mathrm{HNO}_{3}\right)$, i.e., [Lys $\left.+\mathrm{O}_{2}\right]^{-}(\mathrm{m} / z$ 178), $\left[\mathrm{Lys}+\mathrm{HCO}_{3}\right]^{-}(\mathrm{m} / \mathrm{z} 207),[\mathrm{Lys}+\mathrm{COO}(\mathrm{COOH})]^{-}(\mathrm{m} / \mathrm{z} 235)$, $\left[\mathrm{Lys}+\mathrm{NO}_{2}\right]^{-}\left(m / z \text { 192), [Lys }+\mathrm{NO}_{3}\right]^{-}(\mathrm{m} / z$ 208), and [Lys + $\left.\mathrm{NO}_{3}\left(\mathrm{HNO}_{3}\right)\right]^{-}(\mathrm{m} / \mathrm{z}$ 271). The atmospheric ion species serving as reactant ions are listed in Table 2 together with their corresponding $\mathrm{m} / \mathrm{z}$ values.

The abundances of the individual atmospheric ion adducts $[\mathrm{Lys}+\mathrm{R}]^{-}$formed under certain discharge conditions were in good agreement with the concentration of $\mathrm{R}^{-}$formed under those conditions. Under the discharge conditions having the lowest electric field strength leading to abundant generation of atmospheric $\mathrm{O}_{2}^{-}$ion (Figure 2a), the $\mathrm{O}_{2}{ }^{-}$ adduct $\left[\mathrm{Lys}+\mathrm{O}_{2}\right]^{-}$predominates (Figure $3 \mathrm{a}$ ). The abundances of the adduct ions $\left[\mathrm{Lys}+\mathrm{NO}_{2}\right]^{-}$and $\left[\mathrm{Lys}+\mathrm{HCO}_{3}\right]^{-}$ increase the concentrations of the atmospheric ions $\mathrm{NO}_{2}{ }^{-}$ and $\mathrm{HCO}_{3}{ }^{-}$simultaneously, as shown in the medium field strength condition (Figures $2 \mathrm{~b}$ and $4 \mathrm{~b}$ ). In contrast, the adduct ions $\left[\mathrm{Lys}+\mathrm{NO}_{3}\right]^{-}$and $\left[\mathrm{Lys}+\mathrm{NO}_{3}\left(\mathrm{HNO}_{3}\right)\right]^{-}$were generated in abundance under high field strength conditions with atmospheric ions related to $\mathrm{NO}_{3}^{-}$dominating (Figures $2 \mathrm{c}$ and $4 \mathrm{c}$ ). The highest field strength conditions consisting of only the complexes of $\mathrm{NO}_{3}^{-}$with $\mathrm{HNO}_{3}$ as atmospheric ions resulted in the generation of the adduct ion $\left[\mathrm{Lys}+\mathrm{NO}_{3}\left(\mathrm{HNO}_{3}\right)\right]^{-}$(Figure 2d and $4 \mathrm{~d}$ ). The atmospheric ion adducts observed were most likely stably formed via the following three-body reactions with the third body such as $\mathrm{O}_{2}$ or $\mathrm{N}_{2}$ in the ambient discharge area at 760 Torr and/or in the orifice at relatively high pressure $(\approx 760$ Torr). The third body removes the excess energy in the adduct ion, which occurs during the combination of an analyte $\mathrm{M}$ and an atmospheric ion $\mathrm{R}^{-}$.

$$
\mathrm{M}+\mathrm{R}^{-}+P \rightarrow[\mathrm{M}+\mathrm{R}]^{-}+P
$$

(M: analyte, $\mathrm{R}^{-}$: atmospheric ion, $P$ : third body such as $\mathrm{O}_{2}$ or $\mathrm{N}_{2}$ ).

The formation of deprotonated lysine clusters $[n \text { Lys }-\mathrm{H}]^{-}$ is also dependent on the concentration of atmospheric ions with specific acidity. When there were abundant specific atmospheric ions $\mathrm{O}_{2}{ }^{-}, \mathrm{NO}_{2}^{-}$, and $\mathrm{HCO}_{3}^{-}$, the deprotonated ion series were formed in abundance, especially the dimeric ion [2Lys $-\mathrm{H}]^{-}$, (Figure 4a and b). Those ion abundances

Table 2. Atmospheric Ion Species Serving as Reactant Negative Ions, and their Corresponding Proton Affinities

\begin{tabular}{lclc}
\hline Atmospheric ion species & $m / z$ value & $\begin{array}{l}\text { Proton affinity } \\
{\left[\mathrm{kJ} \mathrm{mol}^{-1}\right]}\end{array}$ & References \\
\hline $\mathrm{O}_{2}{ }^{-}$ & 32 & $1477.0 \pm 2.9$ & {$[19]$} \\
$\mathrm{NO}_{2}{ }^{-}$ & 46 & $1423.4 \pm 0.84$ & {$[20]$} \\
$\mathrm{HCO}_{3}^{-}$ & 61 & $<1551.0 \pm 9.2$ & {$[21]$} \\
$\mathrm{COO}^{-}(\mathrm{COOH})$ & 89 & - & - \\
$\mathrm{NO}_{3}{ }^{-}$ & 62 & $1357.7 \pm 0.84$ & {$[23]$} \\
$\mathrm{NO}_{3}{ }^{-}\left(\mathrm{HNO}_{3}\right)$ & 125 & - & - \\
\hline
\end{tabular}

decreased with increasing abundance of the other atmospheric ions involving $\mathrm{NO}_{3}{ }^{-}$(Figure 4c). The dominance of the atmospheric ions consisting of $\mathrm{NO}_{3}{ }^{-}\left(\mathrm{HNO}_{3}\right)$ led to no generation of the deprotonated ion series (Figure 4d). These phenomena can be interpreted using the results of CID experiments for all of the atmospheric ion adducts and the proton affinities of deprotonated lysine and each atmospheric ion. The CID spectra show that the deprotonated lysine $[\text { Lys }-\mathrm{H}]^{-}$can be efficiently formed from the adducts of the atmospheric ions $\mathrm{O}_{2}^{-}, \mathrm{NO}_{2}^{-}$, and $\mathrm{HCO}_{3}^{-}$(Figure $5 \mathrm{a}-\mathrm{c}$ ). The proton affinities of those ions, $\Delta H^{\circ}\left(\mathrm{R}^{-}\left(=\mathrm{O}_{2}^{-}, \mathrm{NO}_{2}^{-}\right.\right.$, and $\left.\left.\mathrm{HCO}_{3}{ }^{-}\right)+\mathrm{H}^{+} \rightarrow \mathrm{HR}\right)=1477.0 \pm 2.9$ [19], $1423.4 \pm 0.84$ [20], and $<1551.0 \pm 9.2 \mathrm{~kJ} \mathrm{~mol}^{-1}$ [21], respectively, are higher than that of $[\mathrm{Lys}-\mathrm{H}]^{-}, 1412.0 \pm 13.0 \mathrm{~kJ} \mathrm{~mol}^{1}$ [22]. In contrast, the other atmospheric ion adducts [Lys $+\mathrm{COO}$ $(\mathrm{COOH})]^{-},\left[\mathrm{Lys}+\mathrm{NO}_{3}\right]^{-}$, and $\left[\mathrm{Lys}+\mathrm{NO}_{3}\left(\mathrm{HNO}_{3}\right)\right]^{-}$result in little formation of $[\text { Lys }-\mathrm{H}]^{-}$, as shown in Figure $5 \mathrm{~d}-\mathrm{f}$. The $\mathrm{NO}_{3}{ }^{-}$has a lower proton affinity than [Lys $\left.-\mathrm{H}\right]^{-}$, $1357.7 \pm 0.84 \mathrm{~kJ} \mathrm{~mol}^{-1}$ [23], whereas there are little information about the proton affinities of $\mathrm{COO}^{-}(\mathrm{COOH})$ and $\mathrm{NO}_{3}{ }^{-}\left(\mathrm{HNO}_{3}\right)$. The results obtained indicate that the formation of $[\mathrm{Lys}-\mathrm{H}]^{-}$is attributed to the efficiency of proton abstraction from lysine by the atmospheric ions with varying individual proton affinity. The atmospheric ions with higher proton affinity can abstract a proton from lysine well to form $[\text { Lys }-\mathrm{H}]^{-}$. Taking into account the matters described above, the deprotonated analyte clusters $[n \mathrm{M}-\mathrm{H}]^{-}$observed here are most likely generated via the following processes:

(a) Initial formation of excited atmospheric ion adducts $[\mathrm{M}+\mathrm{R}]^{-*}$ (reaction 2)

(b) Subsequent formation of the deprotonated analyte $[\mathrm{M}-\mathrm{H}]^{-}$ by the loss of neutral RH due to proton abstraction from analyte $\mathrm{M}$ (reaction 3)

(c) Generation of deprotonated analyte clusters $[n \mathrm{M}-\mathrm{H}]^{-}$ by adiabatic expansion in the vacuum region of the mass spectrometer (reaction 4)

$$
\begin{gathered}
\mathrm{M}+\mathrm{R}^{-} \rightarrow[\mathrm{M}+\mathrm{R}]^{-*} \\
{[\mathrm{M}+\mathrm{R}]^{-*} \rightarrow[\mathrm{M}-\mathrm{H}]^{-}+\mathrm{RH}} \\
{[\mathrm{M}-\mathrm{H}]^{-}+(n-1) \mathrm{M}+P \rightarrow[n \mathrm{M}-\mathrm{H}]^{-}+P}
\end{gathered}
$$

A detailed mechanism for cluster generation by adiabatic expansion can be found in a previous report [9].

\section{Specific Interaction Between Atmospheric Negative Ions and Various Types of Analytes}

In order to obtain further information about the formation of the atmospheric ion adducts $[\mathrm{M}+\mathrm{R}]^{-}$and the resulting deprotonated analytes $[\mathrm{M}-\mathrm{H}]^{-}$, the interaction between 



Figure 5. CID mass spectra of the precursor ions (a) $\left[\mathrm{Lys}+\mathrm{O}_{2}\right]^{-}$, (b) $\left[\mathrm{Lys}+\mathrm{NO}_{2}\right]^{-}$, (c) $\left[\mathrm{Lys}+\mathrm{HCO}_{3}\right]^{-}$, (d) $[\mathrm{Lys}+\mathrm{COO}(\mathrm{COOH})]^{-}$, (e) $\left[\mathrm{Lys}+\mathrm{NO}_{3}\right]^{-}$, and (f) $\left[\mathrm{Lys}+\mathrm{NO}_{3}\left(\mathrm{HNO}_{3}\right)\right]^{-}$ 
Table 3. Product Ions Resulting from the Interaction between Atmospheric Negative Ions and Aliphatic and Aromatic Compounds with Various Functional Groups

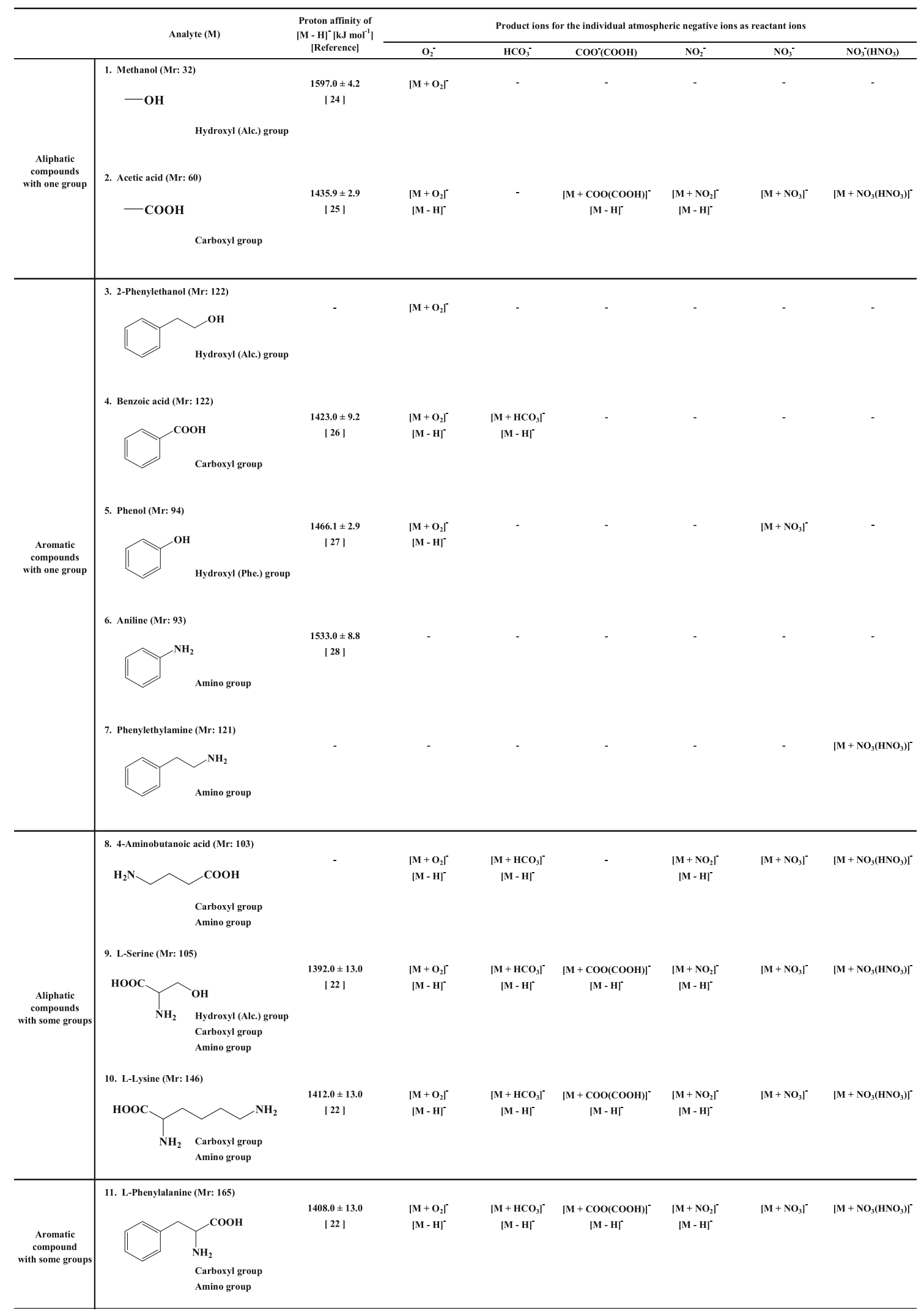


the individual atmospheric ions $\mathrm{R}^{-}$and various types of analytes $\mathrm{M}$ (i.e., aliphatic and aromatic compounds with a variety of functional groups) was investigated using the four discharge conditions used above. The resulting product ions are summarized in Table 3. All the mass spectra used to make Table 3 are shown in Online Resource 1. Individual atmospheric ions can specifically react with compounds having one functional group. Methanol, an aliphatic compound with an alcoholic hydroxyl group (entry 1 in Table 3), was ionized as an adduct with the atmospheric $\mathrm{O}_{2}{ }^{-}$ion, $\left[\mathrm{MeOH}+\mathrm{O}_{2}\right]^{-}$. No deprotonated methanol was observed. This is most likely due to the fact that reaction 3 described in the preceding section does not occur because the proton affinity of $\mathrm{MeO}^{-}$is larger than that of $\mathrm{O}_{2}^{-}$. An aromatic compound with an alcoholic hydroxyl group (i.e., 2-phenylethanol (PE: entry 3 in Table 3)), reacted with only $\mathrm{O}_{2}^{-}$, and the resulting $\left[\mathrm{PE}+\mathrm{O}_{2}\right]^{-}$did not form the deprotonated $\mathrm{PE}$ $[\mathrm{PE}-\mathrm{H}]^{-}$, which is the same as the case of methanol. Taking into account the reason for no formation of $\mathrm{MeO}^{-}$, the large proton affinity of PE compared with $\mathrm{O}_{2}{ }^{-}$can be presumed, while the proton affinity of $\mathrm{PE}$ has not been reported so far. Phenol (entry 5 in Table 3), having a phenolic hydroxyl group, in contrast, interacted with the atmospheric ions $\mathrm{O}_{2}^{-}$and $\mathrm{NO}_{3}{ }^{-}$to generate the corresponding ion adducts $\left[\mathrm{PhOH}+\mathrm{O}_{2}\right]^{-}$and $\left[\mathrm{PhOH}+\mathrm{NO}_{3}\right]^{-}$and the deprotonated phenol $\mathrm{PhO}^{-}$resulting from $\left[\mathrm{PhOH}+\mathrm{O}_{2}\right]^{-}$. Aliphatic and aromatic compounds having a carboxylic group such as acetic acid and benzoic acid attached to $\mathrm{O}_{2}^{-}$, whereas other atmospheric ions reacted with those compounds complementarily (entries 2 and 4 in Table 3). That is, $[\mathrm{AcOH}+\mathrm{COO}$ $(\mathrm{COOH})]^{-},\left[\mathrm{AcOH}+\mathrm{NO}_{2}\right]^{-},\left[\mathrm{AcOH}+\mathrm{NO}_{3}\right]^{-},[\mathrm{AcOH}+$ $\left.\mathrm{NO}_{3}\left(\mathrm{HNO}_{3}\right)\right]^{-}$, and [Benzoic acid $\left.+\mathrm{HCO}_{3}\right]^{-}$were observed. In the case of aniline and phenylethylamine (PEA), which are different types of aromatic compounds from amino groups (entries 6 and 7 in Table 3), only the complex of PEA with $\mathrm{NO}_{3}{ }^{-}\left(\mathrm{HNO}_{3}\right)$ was observed. The adduct ion [PEA+ $\left.\mathrm{NO}_{3}\left(\mathrm{HNO}_{3}\right)\right]^{-}$was apt to form larger complexes involving more $\mathrm{HNO}_{3}$ and PEA, i.e., $\left[\mathrm{PEA}+\mathrm{NO}_{3}\left(\mathrm{HNO}_{3}\right)_{2}\right]^{-}$and [3PEA+ $\left.\mathrm{NO}_{3}\left(\mathrm{HNO}_{3}\right)_{3}\right]^{-}$(see Supplemental Figure S7c and d). On the other hand, aliphatic and aromatic compounds with certain functional groups, such as 4-aminobutanoic acid, L-serine, Llysine, and L-phenylalanine attached to nearly all of the atmospheric ion species, as shown in entries 8-11 in Table 3 .

The results obtained here show that the interaction between the atmospheric ion $\mathrm{R}^{-}$and analyte $\mathrm{M}$, such as whether the atmospheric ion adduct $[\mathrm{M}+\mathrm{R}]^{-}$is formed or not, varies with each given combination of $\mathrm{R}^{-}$and $\mathrm{M}$. This indicates that the formation of $[\mathrm{M}+\mathrm{R}]^{-}$is attributed to not only the concentration of $\mathrm{R}^{-}$generated under the discharge condition used but also the affinity between $\mathrm{R}^{-}$and $\mathrm{M}$. If the affinity of $\mathrm{R}^{-}$for $\mathrm{M}$ is quite low, less formation of $[\mathrm{M}+\mathrm{R}]^{-}$should occur even when sufficiently high concentration of $\mathrm{R}^{-}$exists in the discharge area. The fact that the affinity between $\mathrm{R}^{-}$and $\mathrm{M}$ differs from each combination of $\mathrm{R}^{-}$and $\mathrm{M}$ suggests that the individual $\mathrm{R}^{-}$can be used as reactant ions for specific analyte ionization. However, the factors determining the affinity between $\mathrm{R}^{-}$and $\mathrm{M}$ can not be readily proven because the results shown in Table 3 exhibit that the affinity between $\mathrm{R}^{-}$and $\mathrm{M}$ is not simply dependent upon the chemical properties of $\mathrm{M}$, such as whether the compound is aliphatic or aromatic, or has certain functional groups. Further progress in understanding the relationship between the combination of $\mathrm{R}^{-}$and $\mathrm{M}$ and resulting affinity will require experimental and theoretical studies.

\section{Conclusions}

The interaction between atmospheric negative ions and various types of organic compounds was investigated using atmospheric pressure corona discharge ionization (APCDI) mass spectrometry. Atmospheric negative ions having various proton affinities $\left(\mathrm{O}_{2}^{-}, \mathrm{HCO}_{3}^{-}, \mathrm{COO}^{-}(\mathrm{COOH})\right.$, $\mathrm{NO}_{2}^{-}, \mathrm{NO}_{3}^{-}$, and $\left.\mathrm{NO}_{3}{ }^{-}\left(\mathrm{HNO}_{3}\right)\right)$ served as reactant ions for analyte ionization in APCDI in negative-ion mode. Atmospheric ion formation and the resulting concentrations of individual ion species in the ambient discharge area are dependent upon the discharge conditions (corona voltage and needle angle in relation to the orifice axis, which determines the electric field strength on the needle tip). Individual atmospheric ions $\mathrm{R}^{-}$specifically ionize the analyte $\mathrm{M}$, consisting of aliphatic and aromatic compounds with several functional groups, to atmospheric ion adducts $[\mathrm{M}+\mathrm{R}]^{-}$. Formation of $[\mathrm{M}+\mathrm{R}]^{-}$under certain discharge conditions is attributed to the affinity between $M$ and $\mathrm{R}^{-}$and the concentration of $\mathrm{R}^{-}$produced under these conditions. The adducts of $\mathrm{R}^{-}$with higher proton affinities, such as $\mathrm{O}_{2}^{-}$, $\mathrm{HCO}_{3}{ }^{-}$, and $\mathrm{NO}_{2}{ }^{-}$, furthermore, brought about the production of the deprotonated analytes $[\mathrm{M}-\mathrm{H}]^{-}$due to the efficient proton abstraction from $\mathrm{M}$ by $\mathrm{R}^{-}$. The results obtained here that the affinity between $\mathrm{R}^{-}$and $\mathrm{M}$ differs from each combination of $\mathrm{R}^{-}$and $\mathrm{M}$ suggests that the individual $\mathrm{R}^{-}$can be used as reactant ions for specific analyte ionization, although the factors determining its affinity can not be readily proven. Further studies to understand the relationship between the combination of $\mathrm{R}^{-}$ and $\mathrm{M}$ and resulting affinity are under progress.

\section{Acknowledgments}

M.T. acknowledges the support from Grant-in-Aid for Scientific Research (C) (23550101) from the Japan Ministry of Education, Culture, Sports, and Technology. The authors acknowledge support for this work by a Grant-in-Aid for Research Activity Start-Up of the Japan Society for the Promotion of Science (JSPS) granted under no. 22810025.

\section{References}

1. Takáts, Z., Wiseman, J.M., Gologan, B., Cooks, R.G.: Mass spectrometry Sampling under ambient conditions with desorption electrospray ionization. Science 306, 471-473 (2004)

2. Cody, R.B., Lamamee, J.A., Durstm, H.D.: Versatile new ion source for the analysis of materials in open air under ambient conditions. Anal. Chem. 77, 2297-2302 (2005) 
3. McEwen, C.N., McKay, R.G., Larsen, B.S.: Analysis of solids, liquids, and biological tissues using solids probe introduction at atmospheric pressure on commercial LC/MS instruments. Anal. Chem. 77, 7826$7831(2005)$

4. Jorabchi, K., Weatphall, M.S., Smith, L.M.: Charge assisted laser desorption/ionization mass spectrometry of droplets. J. Am. Soc. Mass Spectrom. 19, 833-840 (2008)

5. Hill, C.A., Thomas, C.L.P.: A pulsed corona discharge switchable high resolution ion mobility spectrometer-mass spectrometer. Analyst 128, 55-60 (2003)

6. Skalny, J.D., Mikoviny, T., Metejcik, S., Mason, N.J.: An analysis of mass spectrometric study of negative ions extracted from negative corona discharge in air. Int. J. Mass Spectrom. 233, 317-324 (2004)

7. Nagato, K., Matusi, Y., Miyama, T., Yamauchi, T.: An analysis of the evolution of negative ions produced by a corona ionizer in air. Int. J. Mass Spectrom. 248, 142-147 (2006)

8. Sekimoto, K., Takayama, M.: Negative ion formation and evolution in atmospheric pressure corona discharges between point-to-plane electrodes with arbitrary needle angle. Eur. Phys. J. D 60, 589-599 (2010)

9. Sekimoto, K., Takayama, M.: Observations of different core water clusters ions $\mathrm{Y}^{-}\left(\mathrm{H}_{2} \mathrm{O}\right)_{n}\left(\mathrm{Y}=\mathrm{O}_{2}, \mathrm{HO}_{x}, \mathrm{NO}_{x}, \mathrm{CO}_{x}\right)$ and magic number in atmospheric pressure negative corona discharge mass spectrometry. $J$. Mass Spectrom. 46, 50-60 (2011)

10. Fehsenfeld, F.C., Ferguson, E.E.: Laboratory studies of negative ion reactions with atmospheric trace constituents. J. Chem. Phys. 61, 31813193 (1974)

11. Atkinson, R., Baulch, D.L., Cox, R.A., Hampson Jr., R.F., Kerr, J.A., Rossi, M.J., Troe, J.: Evaluated kinetic, photochemical and heterogeneous data for atmospheric chemistry: Supplement V. J. Phys. Chem. Ref. Data 26, 578 (1997)

12. Fehsenfeld, F.C., Ferguson, E.E., Bohme, D.K.: Additional flowing afterglow measurements of negative ion reactions of D-region interest. Planet Space Sci. 17, 1759-1762 (1969)

13. Fehsenfeld, F.C., Howard, C.J., Schmeltekopf, A.L.: Gas phase ion chemistry of $\mathrm{HNO}_{3}$. J. Chem. Phys. 63, 2835-2841 (1975)

14. Pack, J.L., Phelps, A.V.: Electron attachment and detachment. Pure $\mathrm{O}_{2}$ at low energy. J. Chem. Phys. 44, 1870-1883 (1966)
15. Chanin, L.M., Phelps, A.V., Biondi, M.A.: Measurements of the attachment of low-energy electrons to oxygen molecules. Phys. Rev. 128, 219-230 (1962)

16. Adams, N.G., Bohme, D.K., Dunkin, D.B., Fehsenfeld, F.C., Ferguson, E.E.: Flowing afterglow studies of formation and reactions of cluster ions of $\mathrm{O}_{2}^{+}, \mathrm{O}_{2}^{-}$, and $\mathrm{O}^{-}$. J. Chem. Phys. 52, 3133-3140 (1970)

17. Finlayson-Pitts, B.J., Pitts Jr., J.N.: Chemistry of the Upper and Lower Atmosphere, 1st edn, pp. 137-138. Academic Press, San Diego (2000)

18. Lide, D.R.: Handbook of Chemistry and Physics, 88th edn, pp. 9-56. CRC Press, Boca Raton (2007)

19. Travers, M.J., Cowles, D.C., Ellison, G.B.: Reinvestigation of the electron sffinities of O2 and NO. Chem. Phys. Lett. 164, 449-455 (1989)

20. Ervin, K.M., Ho, J., Lineberger, W.C.: Ultraviolet photoelectron spectrum of nitrite anion. J. Phys. Chem. 92, 5405-5412 (1988)

21. Bowie, J.H., Depuy, C.H., Sullivan, S.A., Bierbaus, V.M.: Gas-phase reactions of the hydroperoxide and peroxyformate anions. Can. J. Chem. 64, 1046-1050 (1986)

22. O'Hair, R.J., Bowie, J.H., Gronert, S.: Gas phase acidities of the $\alpha$ amino acids. Int. J. Mass Spectrom. Ion Processes 117, 23-36 (1992)

23. Davidson, J.A., Fehsenfeld, F.C., Howard, C.J.: The heats of formation of NO3- and NO3- association complexes with $\mathrm{HNO} 3$ and $\mathrm{HBr}$. Int. $J$. Chem. Kinet. 9, 17-29 (1977)

24. Ramond, T.M., Davico, G.E., Schwartz, R.L., Lineberger, W.C.: Vibronic structure of alkoxy radicals via photoelectron spectroscopy. J. Chem. Phys. 112, 1158-1169 (2000)

25. Muftakhov, M.V., Vasil'ev, Y.V., Mazunov, V.A.: Determination of electron affinity of carbonyl radicals by means of negative ion mass spectrometry. Rapid Commun. Mass Spectrom. 13, 1104-1108 (1999)

26. Caldwell, G., Renneboog, R., Kebarle, P.: Gas phase acidities of aliphatic carboxylic acids, based on measurements of proton transfer equilibria. Can. J. Chem. 67, 611-618 (1989)

27. Gunion, R.F., Gilles, M.K., Polak, M.L., Lineberger, W.C.: Ultraviolet photoelectron spectroscopy of the phenide, benzyl, and phenoxide anions, with ab initio calculations. Int. J. Mass Spectrom. Ion Processes 117, 601-620 (1992)

28. Bartmess, J.E., Scott, J.A., Mclver Jr., R.T.: Scale of acidities in the gas phase from methanol to phenol. J. Am. Chem. Soc. 101, 6046-6056 (1979) 